\title{
A Quantifiable Disease Severity Rating Scale for Frogeye Leaf Spot of Soybean
}

Trey Price, Myra Purvis, and Hunter Pruitt, Macon Ridge Research Station, Louisiana State University Agricultural Center, Winnsboro 71295

Accepted for publication 17 February 2016. Published 22 February 2016.

Price, T., Purvis, M., and Pruitt, H. 2016. A quantifiable disease severity rating scale for frogeye leaf spot of soybean. Plant Health Prog. 17:27-29.

Frogeye leaf spot (FLS) of soybean, caused by Cercospora sojina Hara, has become an annual problem in the mid-southern United States, with estimated losses of \$96 million in Arkansas, Louisiana, Mississippi, Missouri, Tennessee, and Texas during 2014 (Allen et al 2015; USDA-NASS 2014). This is due, in part, to continuous planting of high-yielding, susceptible cultivars and strobilurin fungicide resistance in this pathogen population (Standish et al 2015). Fortunately, producers have resistant and partially resistant cultivars along with triazole fungicides available to combat FLS (Levy et al 2015; Price et al 2014). Resistant cultivars generally develop just a few lesions that do not require management. Nevertheless, producers may overreact when spotting a light FLS infestation in a resistant or partially resistant cultivar resulting in an ill-timed or unnecessary fungicide application. In susceptible cultivars, FLS may develop to levels that require management, but the exact disease severity that triggers a fungicide application at a given growth stage remains elusive. Perceptions of disease severities vary from person to person; therefore, a quantifiable rating scale may be useful to stakeholders in making FLS management decisions.

To obtain images of FLS, hundreds of infected leaflets of susceptible soybean cultivars (e.g., 'Armor DK4744,' 'Hornbeck 4620,' and 'Progeny 4510') were obtained on six dates from midJuly to early August 2015 in two locations in central and northeast Louisiana. Leaflets were immediately stored in plastic bags and placed in coolers at approximately $4{ }^{\circ} \mathrm{C}$. In the laboratory, leaflets were flattened between cardboard under a ten-pound weight for $1 \mathrm{~h}$ prior to placement on blue cloth used as a background. Images were obtained with a 3.2-megapixel Olympus C-760 UltraZoom digital camera (Olympus America, Inc., Center Valley, PA) mounted to a tri-pod at $0.5 \mathrm{~m}$ above the leaflets.

Assess 2.0 (American Phytopathological Society, St. Paul, $\mathrm{MN}$ ), an image analysis software for plant disease quantification, was used to analyze photographs. The automatic analysis panel was used, and "\% Area" was initially selected to define lesion margins. The "Leaf/Lesion" toggle was used to confirm that the leaf was defined as the area of interest (AOI), and that the lesion areas were properly defined. If adjustments were needed, the manual analysis panel was utilized with color planes adjusted to refine AOI and/or lesion area. The percentage of lesion area was recorded as disease severity, and a rating scale was constructed using a minimum of five images for each scale increment (Fig. 1). A second version of the scale was produced by converting the images to grayscale (Fig. 2).

The image analysis program efficiently eliminated insect or other physical damage to leaflets, considering it part of the background. In situations where leaves were not completely flat, there were problems with defining the AOI, and these images were discarded. Efficiently defining the lesion area was problematic in leaves with significant yellowing due to other factors such as virus infection, herbicide damage, or nutrient deficiency, and these images also were discarded. Leaves that were dark green in color, with no other damage other than FLS lesions, were ideal for estimating disease severity.

This scale, and future refined versions that cover a broader range of disease severity, may be used to accurately estimate disease severity in producer fields, which may aid in FLS management decisions. There are additional potential applications in research, such as estimating FLS severity in cultivar screenings and foliar fungicide efficacy trials. Since this scale is quantitative and derived using a non-biased computer program, it may be used instead of or in conjunction with other quantitative or qualitative scales that rely mostly on human perception, and may thereby increase accuracy and statistical validity of results. Potentially, this type of analysis could be used in developing action thresholds for FLS in the future. 


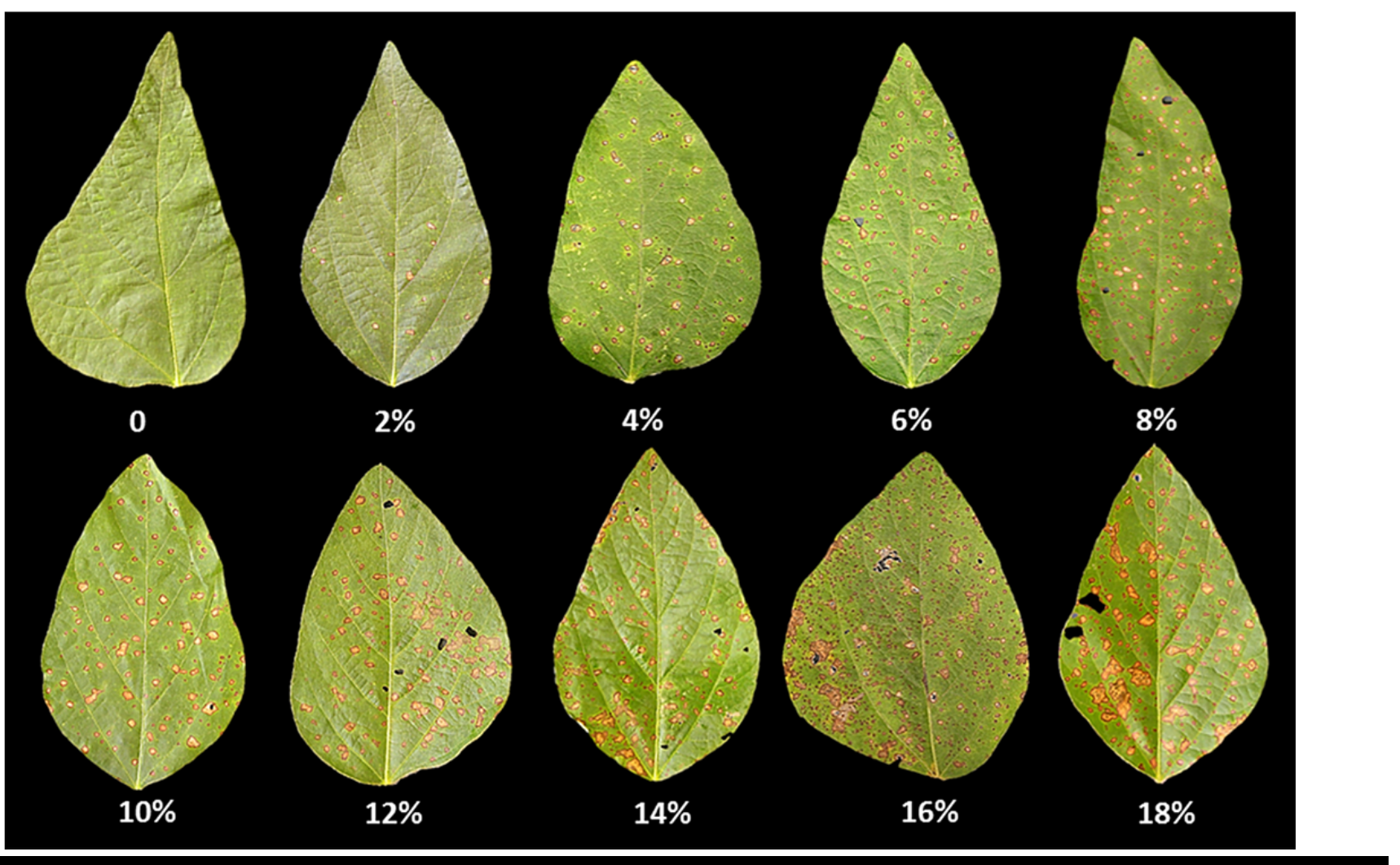

FIGURE 1

Frogeye leaf spot rating scale (color version).

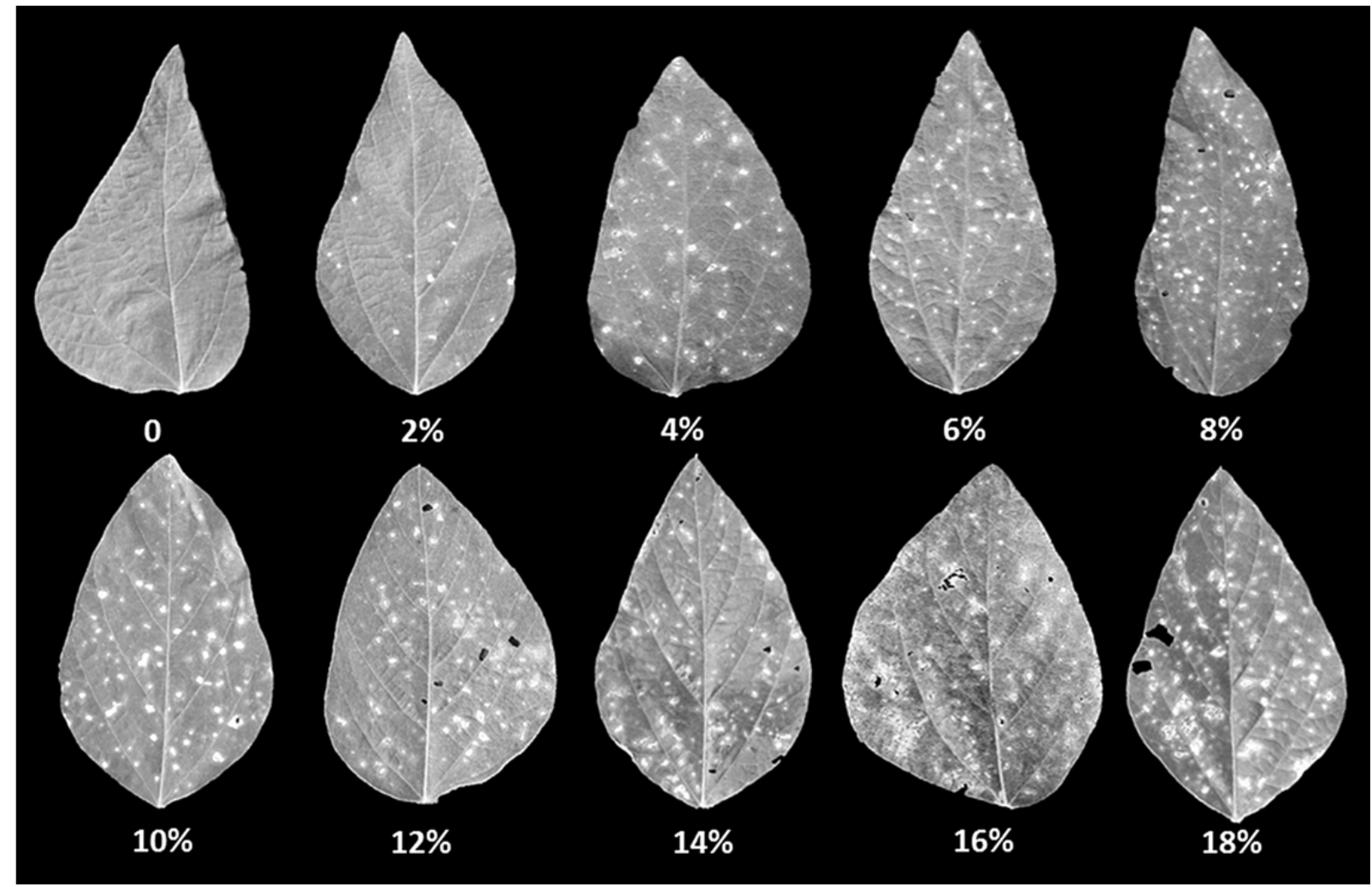

FIGURE 2

Frogeye leaf spot rating scale (grayscale). 


\section{LITERATURE CITED}

Allen, T. W., Damicone, J. P., Dufault, N. S., Faske, T. R., Hershman, D. E., Hollier, C. A., Isakeit, T., Kemerait, R. C., Kleczewski, N. M., Koenning, S. R., Mehl, H. L., Mueller, J. D., Overstreet, C., Price, P., Sikora, E. J., and Young, H. 2015. Southern Unites States disease loss estimates for 2014. Pages 10-13 in: Proceedings of the Southern Soybean Disease Workers, 42nd Annual Meeting, Pensacola, FL.

Levy, R., Padgett, B., Price, T., Harrell, D., Stephenson, D., Webster, E., Bollich, P., Hollier, C., Davis, J.., Buckley, B., Woodard, C., and
Normand, K. 2015. 2016 Soybean Variety Trials and Production Practices. Publ. No. 2269. LSU AgCenter, Baton Rogue, LA.

Price, P., Padgett, G. B., and Purvis, M. A. 2014. The efficacy of selected fungicides on frogeye leaf spot, 2013. Plant Dis. Manag. Rep. 8:FC222 doi:10.1094/PDMR08.

Standish, J. R., Tomaso-Peterson, M., Allen, T. W., Sabanadzovic, S., and Aboughanem-Sabanadzovic, N. 2015. Occurrence of QoI fungicide resistance in Cercospora sojina from Mississippi soybean. Plant Dis. 99:1347-1352.

United States Department of Agriculture, National Agricultural Statistics Service (USDA-NASS). 2014. QuickStats database. Retrieved from www.nass.usda.gov. 